\title{
Frontal Lobe Dysfunction in a Depressed Patient Who Survived a Suicide Attempt by Jumping from the Bridge on the Han River
}

\author{
Kiwon Kim ${ }^{1}$ and Hong Jin Jeon ${ }^{1,2} \bowtie$ \\ 1'Department of Psychiatry, Depression Center, Samsung Medical Center, Sungkyunkwan University School of Medicine, Seoul, Republic of Korea \\ ${ }^{2}$ Department of Health Sciences \& Technology, Department of Medical Device Management \& Research, and Department of Clinical Research \\ Design \& Evaluation, Samsung Advanced Institute for Health Sciences \& Technology (SAIHST), Sungkyunkwan University, Seoul, \\ Republic of Korea
}

Suicide attempts at the Han river are rapidly increasing, which are 4.11 times from 2005 to 2015, whereas the rate of completed suicide in South Korea increased 1.07 times during the same period. However, few studies have been conducted on the issue because many suicide attempters were seriously injured after a fall in the Han river. We present a case of a patient with major depressive disorder (MDD) who attempted suicide and minimally injured after jumping from the bridge at the Han river. We could assess his psychological and neurocognitive functions before and immediately after his attempt. From this case, we can identify that higher cognitive aspect of executive dysfunction, especially in the frontal domain of selective attention and inhibition, may be associated with his suicide attempt. In conclusion, we suggest psychiatric treatments for cognitive impulsiveness and safety barriers at the bridge to prevent suicide attempts of patients with MDD.

Psychiatry Investig 2017;14(6):904-908

Key Words Biological psychiatry, Cognitive sciences, Depressive disorder, Suicide.

\section{INTRODUCTION}

More than 800,000 people die due to suicide every year and millions of people are affected by bereavement following suicide. ${ }^{1}$ The suicide rate in South Korea is the highest among the OECD countries, and it is the leading cause of death in 10-39 year-old-age groups, although the suicide rate continuously decreased to $26.5 / 100,000$ in 2015, compared with $31.7 / 100,000$ in $2011 .{ }^{2}$ On the contrary, suicide attempts at the bridge on the Han river have been rapidly increasing over the last decade from 132 persons in 2005 to 543 persons in 2015 (4.11 times), compared with completed suicide rates in South Korea during the same period which increased from $24.7 / 100,000$ to 26.5/100,000 (1.07 times). ${ }^{3}$ From the study of the strategic system, it is evident that it is necessary to prevent suicidal falls

\footnotetext{
Received: October 30, 2016 Accepted: January 4, 2017

Available online: August 25, 2017

$\triangle$ Correspondence: Hong Jin Jeon, MD, PhD

Department of Psychiatry, Depression Center, Samsung Medical Center, Sungkyunkwan University School of Medicine, 81 Irwon-ro, Gangnam-gu, Seoul 06351, Republic of Korea

Tel: +82-2-3410-3586, Fax: +82-2-3410-0050, E-mail: jeonhj@skku.edu

(a) This is an Open Access article distributed under the terms of the Creative Commons Attribution Non-Commercial License (http://creativecommons.org/licenses/by$\mathrm{nc} / 4.0$ ) which permits unrestricted non-commercial use, distribution, and reproduction in any medium, provided the original work is properly cited.
}

from the bridges over the Han river by Fire and Disaster Headquarters (Figure 1). ${ }^{4}$ It is important to understand why they attempt suicide by jumping into the Han river in order to develop an effective system to prevent suicide attempts.

In this paper, we will present a case of a male patient who survived a suicidal attempt by jumping into the Han river, and minimally injured after jumping from the bridge at the Han river. The patient read this report before its submission, and signed the informed consent form for publication.

\section{CASE}

A male patient in his early $40 \mathrm{~s}$, visited the depression clinic after surviving a suicide attempt, by jumping into the Han river from the Seongsudaegyo bridge in September 2015. He had a previous history of receiving psychiatric treatment for depression, but he had been working well in a large company and he had few family problems. The incidence occurred 10 days prior to his outpatient visit, and he recalled it in detail.

Two months ago, he stopped his medication for depression due to his resistance to taking pills, but he could maintain his daily routine very well for more than 40 days. However, he and his wife observed a difference 6 days before he threw himself into the Han river, accompanied by excessive anxiety and 
insomnia. Four days before the patient's suicide attempt, his wife felt that her husband was very dull, had difficulty in organizing his own thoughts, like an absent-minded person. Three days before the fall, he seemed to focus on some other ideas and had a sad face. The day before he jumped into the
Han river, he conversed with his wife in an inappropriate manner and he wandered outside for 1 hour without any purpose.

His wife filed a missing report with the police, and she received a phone call from the police officer telling about the news of his survival from Seonsudaegyo. He was found in the river
Figure 1. The number of suicide attempts by jumping from bridges of the Han river each year (2003-2015).

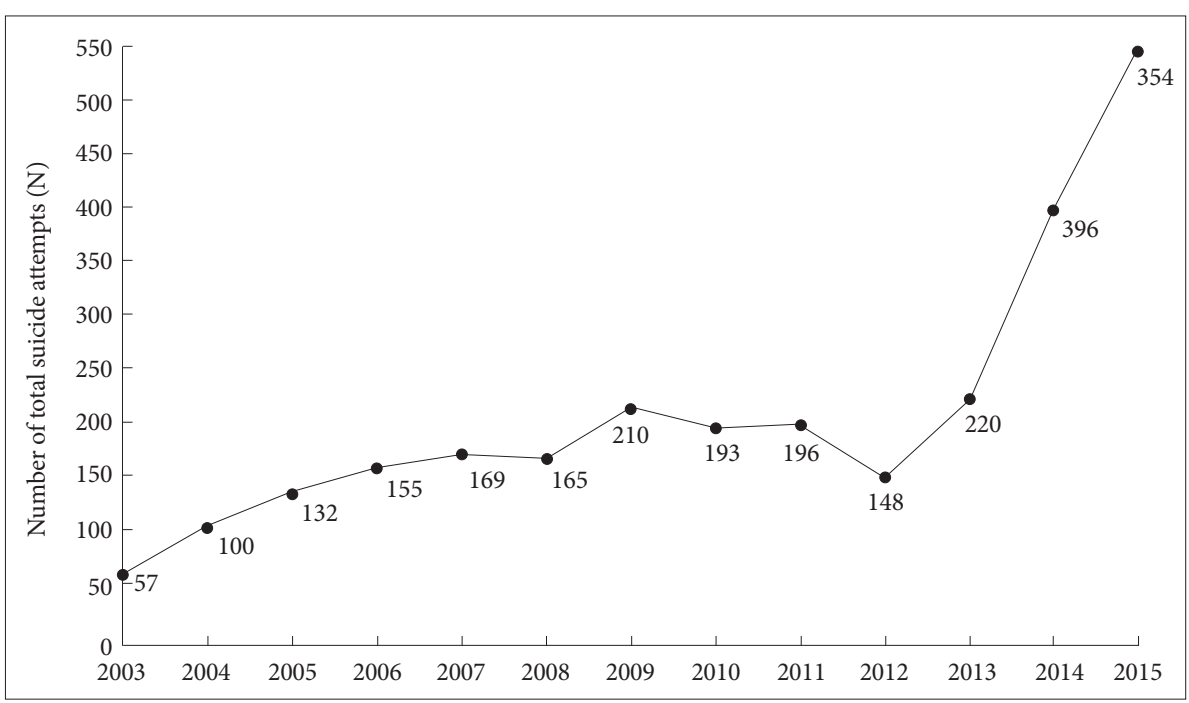

Table 1. Characteristics of psychological and neurocognitive functions tests comparing depressive episode free from a suicide attempt and episode of a suicide attempt in September 2015

\begin{tabular}{|c|c|c|}
\hline Test profile & September 2013 & October 2015 \\
\hline HAM-D & 8 & 6 \\
\hline HAM-A & 14 & 5 \\
\hline BDI & 2 & 7 \\
\hline BAI & Not done & 3 \\
\hline MDQ & 5 & 1 \\
\hline \multicolumn{3}{|l|}{ Neurocognitive function test } \\
\hline Attention: TMT-A & Normal & Normal \\
\hline Attention: TMT-B & Normal & Normal \\
\hline Attention: Visual Continuous Performance test & $\begin{array}{l}\text { Normal in } \\
\text { Bender Gestalt Test, } \\
\text { Clock Drawing Test }\end{array}$ & Normal \\
\hline \multicolumn{3}{|l|}{ Memory: Verbal learning test (RAVLT) } \\
\hline Free recall & Normal & Normal \\
\hline Delayed recall & Normal & Normal \\
\hline Recognition & Normal & Normal \\
\hline \multirow[t]{2}{*}{ Frontal lobe and higher cognitive function test } & Normal & $\begin{array}{l}\text { Abnormal (moderately atypical) } \\
\text { Color Word Test }\end{array}$ \\
\hline & $\begin{array}{l}\text { Reasoning and problem solving: normal } \\
\text { (similarities, visual puzzle, matrix reasoning) } \\
\text { Alternating square and triangle: normal } \\
\text { Letter cancellation: normal }\end{array}$ & $\begin{array}{l}\text { - Word (Black): normal } \\
\text { - Color only: normal } \\
\text { - Color word: abnormal } \\
\text { - Word of color word: abnormal } \\
\text { - Color of color word: abnormal }\end{array}$ \\
\hline
\end{tabular}

HAM-D: Hamilton Rating Scale for Depression, HAM-A: Hamilton Rating Scale for Anxiety, BDI: Beck Depression Inventory, BAI: Beck Anxiety Inventory, MDQ: The Mood Disorder Questionnaire, TMT-A: Trail Making Test-A, TMT-B: Trail Making Test-B, RAVLT: Rey Auditory Verbal Learning Test 


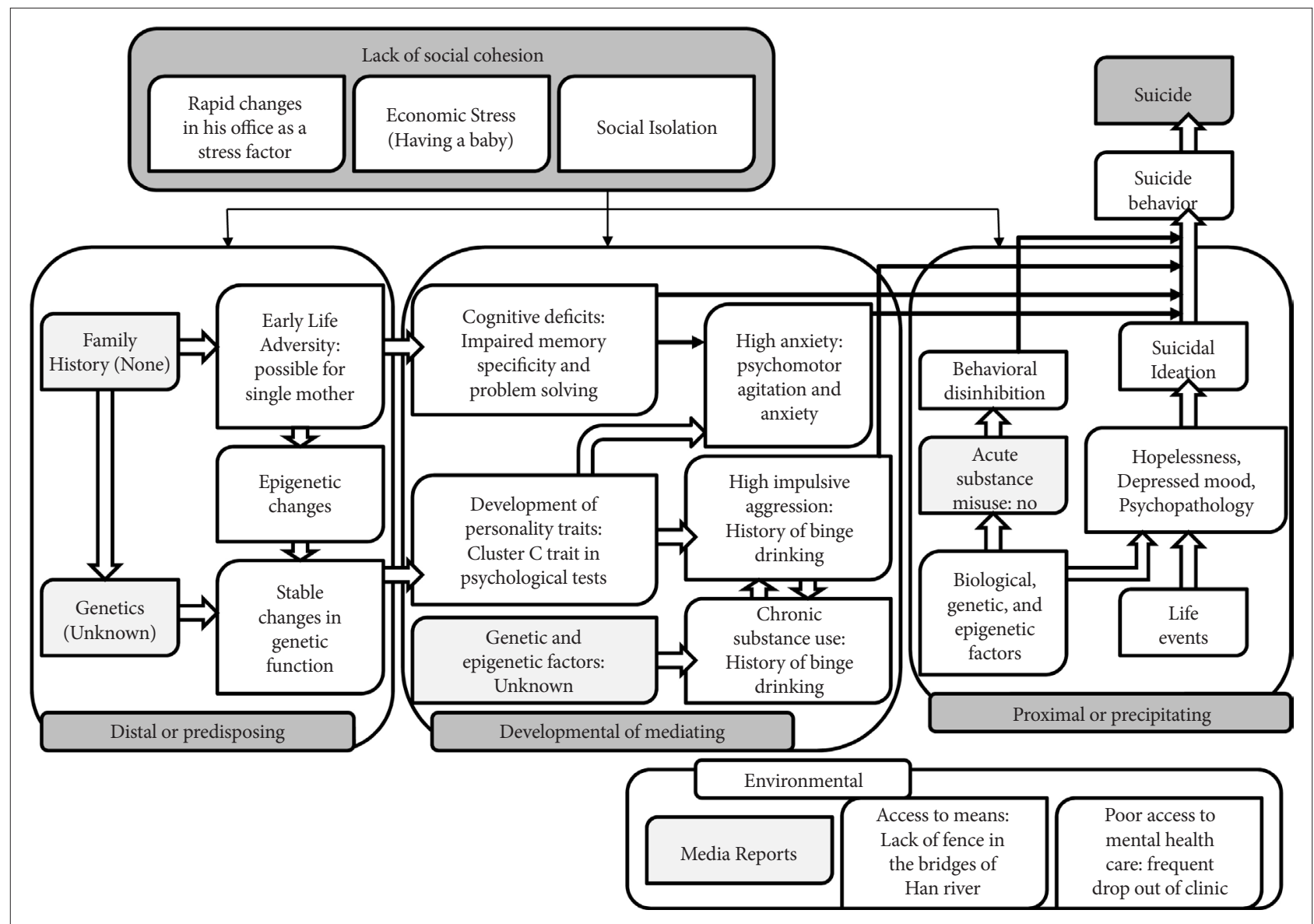

Figure 2. Risk cascades in the suicide related behavior.

immediately after his suicide attempt at $8 \mathrm{pm}$, and he was taken to the closest emergency room for treatment. Fortunately, he did not hurt his head and only suffered a hemopneumothorax, and he was recommended to get admitted into the closed ward of the psychiatric unit, but he and his wife refused to get him admitted. He only received $5 \mathrm{mg}$ of aripiprazole and $1 \mathrm{mg}$ of benztropine, twice for nine days from the psychiatric unit. This was his 5th depressive episode with a prominent acute aggravated course after discontinuation of medication.

His first episode occurred in June 2008, and it was characterized by depressive mood with evident insomnia and appetite loss accompanied by psychomotor agitation. It was not relieved by paroxetine $20 \mathrm{mg}$ and quetiapine $25 \mathrm{mg}$, and he had a slightly paranoid idea of being followed by the police, which led to titration of quetiapine to $100 \mathrm{mg}$. After switching to aripiprazole monotherapy at $15 \mathrm{mg}$, he finally felt comfortable but he discontinued the treatment. In July 2013, he visited our department for the 2nd episode with evident psychomotor retardation, inappropriate conversations with accompanying insomnia, and he was recommended to get admitted but he refused to do so. Therefore, he received his medication up to
$15 \mathrm{mg}$ of aripiprazole and he discontinued his treatment again in November 2013. In October 2014, he experienced excessive guilt, paranoid idea, psychomotor agitation, and he lost himself after getting out of his office and was found with drug intoxication with his own psychiatric medications, without precise memory of his attempt. His psychomotor retardation continued for 15 days, but it was relieved after maintaining a dose of $20 \mathrm{mg}$ of aripiprazole, but he stopped his treatment immediately after obtaining relief and revisited the department in August 2015 for the 4th depressive episode. He visited our department for the medical certificate required by the police station but kept the reason a secret. He was suffering from psychomotor retardation accompanied by binge drinking, but he denied his emotional problems.

We could observe that the psychological and cognitive aspects differed between each episode, one of them (in October 2015) related to his suicide attempt, the one immediately after his jump into the Han river (Table 1). He was found to be a rigid and concrete person in both psychological tests, mostly denying his emotional problem, and did not consider himself depressed, represented by a low score on the subjective and 
objective assessment scale for depression and anxiety. However, he seemed to be sensitive to criticism by others and was vulnerable to refusals in social situations. He was reported to becoming easily overwhelmed by emotional stimuli in case of unavoidable circumstances. Such vulnerability, which was shown by the score of 36 on the PANSS in September 2013, suggests his cognitive impulsiveness with lack of flexibility in shifting his viewpoint. The difference observed in the neurocognitive function test should be emphasized with frontal lobe dysfunction, which could be characterized by cognitive inhibition and appropriate judgement. He showed no evidence of brain injury or contusion.

With respect to the individual risk factors, being raised by a single mother could possibly be associated with early life adversities, which could have led to epigenetic changes along with stable changes in genetic function. These cascades (Figure 2) could have also led to mediation of individual risk factors observed in his psychological test results, cognitive deficits (problem solving and difficulty in changing his cognitive approach) and a recent history of impaired memory close to his suicide attempt. He repeatedly showed a cluster $\mathrm{C}$ personality trait in psychological tests. Frequent psychomotor agitation and anxiety symptom aggravation observed during the depressive episode could have acted as mediating risk factors and binge alcohol drinking history may be related to high impulsive aggression and chronic substance use.

\section{DISCUSSION}

Here, we can identify significant characteristics of suicidal behavior in a MDD patient, dependent of frontal lobe dysfunctions and independent of the depressive symptom severity. This individual survived a fall into the Han river, and realized his poor judgement in committing suicide while he was falling from the bridge. These important findings suggest the need of efficient preventive approaches to a suicide attempt for impaired judgement and cognitive functions, especially due to dysfunction in the frontal domain, and decreased cognitive inhibition during a depressive episode with suicide attempt.

The association between MDD with other mood disorders and suicide has been reported consistently, including an association of $60 \%$ in the autopsy report. ${ }^{5}$ However, there is no proposed risk factor for suicide which has a sufficient predictive power, ${ }^{6}$ between biological susceptibility related to the serotonin system and dysfunctional neural networks. Extending the stress-diathesis model suggesting that individuals with susceptibility (diathesis) to suicidal behavior are at risk of attempting suicide after exposure to stress, ${ }^{7-9}$ various suicide specific neurocognitive characteristics have been proposed. ${ }^{10-14}$ Past history of depressive illness ${ }^{15}$ combined with distinct al- terations in value-based decision making ${ }^{16}$ led to a suicidal attempt in this case, as they have recently been researched in various study groups. ${ }^{17}$ Our previous study indicated that reduced fronto-subcortical circuit, which includes regions associated with executive function and impulsivity, appears to have a role in the emergence of suicidal ideation in MDD patients. $^{18}$

We assessed three different domains of executive functions, set shifting, working memory, and selective attention and response inhibition to examine the independent association of change. ${ }^{19,20}$ We examined set shifting with the trail making test, working memory with the digit span test, and selective attention and response inhibition with the color-word test. Cognitive deficits in executive functions have been proposed as candidate "endophenotypes" for suicidality. ${ }^{21}$ Also, individuals with executive dysfunction especially in response inhibition as in our case, may have more difficulty in controlling thoughts of self-harm and may move to more adaptive forms of problem solving. Also, suicidality is associated with impaired social problem solving, ${ }^{22}$ related to difficulty in resisting the urge to self-harm. The result of this patient's psychological test strongly suggests impaired executive function in the domain of selective attention and conflict resolution, based on independent flaws in the color-word test. This case suggests the need for psychiatric evaluation and treatments for frontal lobe dysfunction in MDD patients.

We also suggest safety barriers on the bridge to prevent suicide attempts in MDD patients, because their frontal lobe dysfunctions interfere logical understanding for their risk at the bridge. Suggestions written over the bridges to prevent the individuals from attempting suicide may not work well, and may tempt people to visit such a spot. Considering the limitations in identifying the individuals who are vulnerable to suicidal behavior especially with cognitive impulsiveness, restricting access to lethal means, based on the previous effectiveness from other access restrictions, ${ }^{23,24}$ like fencing along the bridges over the Han river, would be much more helpful and effective with respect to short-term outcomes.

\section{REFERENCES}

1. World Health Organization: Suicide Prevention (SUPRE). Geneva; WHO Press; World Health Organization; 2014.

2. The Statistics Korea (KOSTAT). Causes of Death Statistics in 2015. Daejeon: The Statistics Korea (KOSTAT); 2016.

3. The Statistics Korea (KOSTAT). Causes of Death Statistics in 2014. Daejeon: The Statistics Korea (KOSTAT); 2015.

4. Park SH. Han River rescue team struggles with increased suicide attempts. The Hankyoreh; August 11th; 2013.

5. Hong JJ. Epidemiologic stuides on depression and suicide. J Korean Med Assoc 2012;55:322-328.

6. Pokorny AD. Prediction of suicide in psychiatric patients. Report of a prospective study. Arch Gen Psychiatry 1983;40:249-257. 
7. Mann JJ, Arango V. Integration of neurobiology and psychopathology in a unified model of suicidal behavior. J Clin Psychopharmacol 1992; 12:2S-7S.

8. Mann JJ. Neurobiology of suicidal behaviour. Nat Rev Neurosci 2003; 4:819-828.

9. Mann JJ, Waternaux C, Haas GL, Malone KM. Toward a clinical model of suicidal behavior in psychiatric patients. Am J Psychiatry 1999;156: 181-189.

10. Tarsafi M, Kalantarkousheh SM, Lester D. The defeat-entrapment theory versus Beck's hopelessness theory of depression and suicidality: a cross-national analysis in Iran and the United States. Int J Soc Psychiatry 2015;61:777-780.

11. van Heeringen $K$. The neurobiology of suicide and suicidality. Can J Psychiatry 2003;48:292-300.

12. Rudd MD. The suicidal mode: a cognitive-behavioral model of suicidality. Suicide Life Threat Behav 2000;30:18-33.

13. Beck AT, Weishaar ME. Suicide risk assessment and prediction. Crisis 1990;11:22-30.

14. Adler A, Bush A, Barg FK, Weissinger G, Beck AT, Brown GK. A mixed methods approach to identify cognitive warning signs for suicide attempts. Arch Suicide Res 2016:1-11.

15. Holma KM, Melartin TK, Haukka J, Holma IA, Sokero TP, Isometsa ET. Incidence and predictors of suicide attempts in DSM-IV MDD: a five-year prospective study. Am J Psychiatry 2010;167:801-808.

16. Richard-Devantoy S, Olie E, Guillaume S, Bechara A, Courtet P, Jollant F. Distinct alterations in value-based decision-making and cognitive control in suicide attempters: toward a dual neurocognitive model. J Affect Disord 2013;151:1120-1124.

17. Jollant F, Bellivier F, Leboyer M, Astruc B, Torres S, Verdier R, et al. Impaired decision making in suicide attempters. Am J Psychiatry 2005; 162:304-310.

18. Myung W, Han CE, Fava M, Mischoulon D, Papakostas GI, Heo JY, et al. Reduced frontal-subcortical white matter connectivity in association with suicidal ideation in MDD. Transl Psychiatry 2016;6:e835.

19. Liu-Ambrose T, Davis JC, Nagamatsu LS, Hsu CL, Katarynych LA, Khan KM. Changes in executive functions and self-efficacy are independently associated with improved usual gait speed in older women. BMC Geriatr 2010;10:25.

20. Miyake A, Friedman NP, Emerson MJ, Witzki AH, Howerter A, Wager TD. The unity and diversity of executive functions and their contributions to complex "Frontal Lobe" tasks: a latent variable analysis. Cogn Psychol 2000;41:49-100.

21. Mann JJ, Arango VA, Avenevoli S, Brent DA, Champagne FA, Clayton $\mathrm{P}$, et al. Candidate endophenotypes for genetic studies of suicidal behavior. Biol Psychiatry 2009;65:556-563.

22. Pollock LR, Williams JM. Problem-solving in suicide attempters. Psychol Med 2004;34:163-167.

23. Myung W, Lee GH, Won HH, Fava M, Mischoulon D, Nyer M, et al. Paraquat prohibition and change in the suicide rate and methods in South Korea. PLoS One 2015;10:e0128980.

24. Blaustein M, Fleming A. Suicide from the Golden Gate Bridge. Am J Psychiatry 2009;166:1111-1116. 